\title{
Regional and Cellular Mapping of cAMP Response Element- Mediated Transcription during Naltrexone-Precipitated Morphine Withdrawal
}

\author{
Tamara Z. Shaw-Lutchman, ${ }^{1,2}$ Michel Barrot, ${ }^{1}$ Tanya Wallace, ${ }^{2}$ Lauren Gilden, ${ }^{2}$ Venetia Zachariou, ${ }^{1,4}$ \\ Soren Impey, ${ }^{3}$ Ronald S. Duman, ${ }^{2}$ Daniel Storm, ${ }^{3}$ and Eric J. Nestler ${ }^{1}$ \\ ${ }^{1}$ Department of Psychiatry and Center for Basic Neuroscience, The University of Texas Southwestern Medical Center, \\ Dallas, Texas 75390-9070, 2Interdepartmental Neuroscience Program and Laboratory of Molecular Psychiatry, Yale \\ University School of Medicine, New Haven, Connecticut 06508, '3epartment of Pharmacology, University of Washington, \\ Seattle, Washington 98195, and 4Department of Pharmacy, University of Patras School of Health, Patras, Greece 26500
}

Chronic opiate exposure is associated with upregulation of the cAMP signaling pathway and the transcription factor cAMP response element-binding protein in the locus ceruleus (LC) and certain other brain areas. To determine whether these adaptations ultimately affect transcription mediated by the cAMP response element (CRE), we induced morphine dependence in CRE-LacZ transgenic mice and performed a regional and cellular mapping of $\beta$-galactosidase ( $\beta$-gal) expression during naltrexone-precipitated withdrawal. Consistent with our model of opiate dependence, $\beta$-gal expression increased in the LC, but decreased in the lateral ventral tegmental area (VTA) and dorsal raphe nucleus (DRN). In addition, withdrawal increased $\beta$-gal expression in the continuum of the extended amygdala and nucleus accumbens, macrostructures associated with the coupling of emotional stimuli to motor and autonomic responses. At the cellular level, in the central nucleus of the amygdala, $\beta$-gal was found in cells both with and without $\mu$ opioid receptors as well as in corticotropin-releasing factorexpressing cells. In nucleus accumbens, $\beta$-gal was expressed in several major subpopulations of neurons. In LC, $\beta$-gal expression was induced predominantly in tyrosine hydroxylaseexpressing cells, whereas in the VTA and DRN the majority of cells expressing $\beta$-gal were nonmonoaminergic. These results show that molecular adaptations to chronic morphine alter CRE-mediated transcription during opiate withdrawal in physiologically salient regions involved in arousal, reward, mood, and affective responses. We propose that CRE-mediated transcription serves as a functional marker for neuronal plasticity during withdrawal. CRE-mediated transcription may itself contribute to re-establishing homeostasis in the organism through target gene regulation in these regions.

Key words: CREB; cAMP; locus ceruleus; nucleus accumbens; amygdala; ventral tegmental area; dorsal raphe; gene expression
Chronic use of drugs of abuse is thought to induce homeostatic neuronal adaptations and synaptic plasticity in specific brain regions, changes that ultimately contribute to the addictive phenotype (Nestler et al., 1993; Berke and Hyman, 2000; Nestler, 2001). In the principal noradrenergic nucleus of the hindbrain, the locus ceruleus (LC), chronic morphine increases levels of cAMP response element-binding protein (CREB) (Widnell et al., 1994), a transcription factor whose activity has been implicated in the development of morphine dependence (Maldonado et al., 1996; Lane-Ladd et al., 1997). CREB binds to the cAMP response element (CRE) present in many genes and, when phosphorylated, alters their transcription (Montminy, 1997; Shaywitz and Greenberg, 1999). Changes in CREB-mediated transcription underlie a form of synaptic plasticity associated with learning and the expression of long-term memory (Martin and Kandel, 1996; Yin and Tully, 1996; Silva and Murphy, 1999).

The phosphorylation state of CREB is determined by several intracellular signal transduction pathways including the cAMP pathway. In the LC, the phosphorylation of CREB is homeostati-

\footnotetext{
Received July 27, 2001; revised Jan. 3, 2002; accepted Jan. 10, 2002.

This work was supported by grants from the National Institute on Drug Abuse.

Correspondence should be addressed to Eric J. Nestler, Department of Psychiatry, The University of Texas Southwestern Medical Center, 5323 Harry Hines Boulevard, Dallas, TX 75390-9070. E-mail: eric.nestler@utsouthwestern.edu. Copyright (C) 2002 Society for Neuroscience $0270-6474 / 02 / 223663-10 \$ 15.00 / 0$
}

cally regulated by activity at the $\mu$ opioid receptor ( $\mu \mathrm{OR})$, which inhibits the cAMP pathway via the inhibitory G-protein $G_{i}$. Exogenous opiates acutely inhibit CREB phosphorylation in the LC by inhibiting adenylyl cyclase activity (Duman et al., 1988; Guitart et al., 1992). Chronic morphine, however, induces expression of particular components of the cAMP signaling pathway, including adenylyl cyclases I and VIII and protein kinase A (PKA) catalytic and regulatory subunits (Nestler and Tallman, 1988; Lane-Ladd et al., 1997; Nestler and Aghajanian, 1997), so that the phosphorylation state of CREB gradually recovers toward normal levels during the course of chronic opiate administration (Guitart et al., 1992). Removal of the opiate (and its inhibition of the cAMP pathway) reveals the consequences of the upregulated cAMP pathway, namely, a robust increase in CREB phosphorylation.

Chronic morphine treatment has also been shown to upregulate the cAMP pathway in regions of the brain other than the $\mathrm{LC}$, including the nucleus accumbens (NAc, also known as ventral striatum), amygdala, dorsal raphe nucleus (DRN), and ventral tegmental area (VTA) (Terwilliger et al., 1991; Bonci and Williams, 1997; Jolas et al., 2000). However, the functional impact of these adaptations on the transcriptional activity of CREB in these brain areas during chronic opiate administration and opiate withdrawal is not known.

To determine whether opiate exposure regulates CREB- 
mediated transcription, we induced morphine dependence and then precipitated withdrawal with the opioid receptor antagonist naltrexone in transgenic CRE-reporter mice. These mice bear constructs in which the reporter gene, LacZ [encoding $\beta$-galactosidase $(\beta$-gal)], is under the control of CRE-consensus elements. These reporter mice have been used to demonstrate the involvement of CRE-mediated transcription in a variety of physiologic and pharmacologic processes related to emotional learning or development (Impey et al., 1998; Pham et al., 1999; Thome et al., 2000). Here, we use the CRE-LacZ mice to map the brain regions and neuronal cell types in which CRE-mediated transcription is regulated during opiate withdrawal to identify neural circuits in which persistent functional changes occur that may underlie certain behavioral features of opiate addiction.

\section{MATERIALS AND METHODS}

Transgenic mouse line. The CRE-reporter mouse used in this study contains six CRE-consensus sequences in tandem, upstream of a minimal Rous sarcoma virus promoter (Impey et al., 1998). Male heterozygote transgenic mice (line 37) were out-crossed to wild-type C57/BL6 mice. Genotyping was performed by PCR. Animals were bred and maintained under a $12 \mathrm{hr}$ dark/light cycle with food and water ad libitum. Male and female mice heterozygous for the transgenic sequence between the ages of 8 and 12 weeks were used for all experiments. For each experimental animal, a littermate of the same gender and bearing the reporter transgene was used as a control. This was done to take into account the variability of reporter expression among litters.

Drug administration. Morphine was administered chronically in two ways: by repeated intraperitoneal injection or by repeated subcutaneous pellet implantation. In the chronic injection paradigm, transgenic mice received twice-daily intraperitoneal injections of an escalating dose of morphine sulfate over $8 \mathrm{~d}(10,20,40,80,100,120,140,140 \mathrm{mg} / \mathrm{kg})$. Control mice received saline injections. Twelve hours after the last injection, mice received an intraperitoneal injection of either saline or naltrexone $(50 \mathrm{mg} / \mathrm{kg}$ ) (Sigma, St. Louis, MO). We waited $12 \mathrm{hr}$ to limit any influence of the last morphine injection per se on CRE activity. This wait may have allowed some spontaneous withdrawal to occur (although no signs of withdrawal were evident), which is why a pelleting paradigm was used in subsequent experiments: a pelleting paradigm enabled a much clearer distinction between effects of chronic morphine and effects of withdrawal. Mice on which Fos immunohistochemistry was performed also received an escalating dose of chronic morphine via injections every $8 \mathrm{hr}(20,40,60,80,100,100,100)$ followed by naltrexone $2 \mathrm{hr}$ after the last injection. In the pellet paradigm, on day 1 transgenic mice were anesthetized with inhaled isofluorane and implanted subcutaneously with either a $25 \mathrm{mg}$ morphine base pellet or a physically similar colloid sham pellet. An identical procedure was performed on day 3 . On day 6 , mice received an intraperitoneal injection of saline or naltrexone (100 $\mathrm{mg} / \mathrm{kg}$ ). A higher dose of naltrexone was used in the pelleting procedure to induce maximal levels of withdrawal in the presence of continuous morphine administration (Rasmussen et al., 1990). In all experiments, animals were injected $4 \mathrm{hr}$ later (to permit reporter gene expression) with an overdose of pentobarbital. Animals were perfused transcardially with saline followed by $4 \%$ paraformaldehyde in $0.1 \mathrm{M}$ phosphate buffer, post-fixed for $12 \mathrm{hr}$, then cryopreserved in $25 \%$ glycerol for $12 \mathrm{hr}$. Brains were sectioned at $40 \mu \mathrm{m}$ intervals in PBS.

Behavioral scoring. Several measures of opiate withdrawal were assessed in mice that received morphine by repeated injections or by the pelleting procedure. The mice were weighed before the final saline or naltrexone injection, the behavior was then scored for $30 \mathrm{~min}$, and the mice were weighed again. The number of jumps, wet dog shakes, backward locomotion, and paw tremors were recorded. Weight loss was measured as a percentage of the preinjection weight. General tremors and ptosis were scored as present (1) or absent (0) for each $5 \mathrm{~min}$ period over the $30 \mathrm{~min}$ of scoring.

Single- and double-labeling immunohistochemistry. LacZ immunohistochemistry was performed using a rabbit polyclonal anti- $\beta$-gal antibody (1:500; 5-prime, 3-prime Inc., Boulder, CO) for single-labeling, or a mouse monoclonal antibody (1:500; Sigma) for double-labeling. Immunohistofluorescence was performed for the $\mu$ opioid receptor $(1: 200$; Chemicon, Temecula, CA), tyrosine hydroxylase (TH) (1:200; Sigma), serotonin (1:200; Chemicon), choline acetyltransferase (1:200; Diasorin,
Stillwater, MN), calbindin (1:200; Chemicon), or S-100 (1:200; Sigma) and visualized using Alexa fluorophore-labeled secondary antibodies (Molecular Probes, Eugene, OR). Sections were mounted in Vectashield mounting media with a 4',6'-diamidino-2-phenylindole counterstain (Vector Laboratories, Burlingame, CA). Quantification and localization of $\beta$-gal expression was performed on either fluorescent light microscopy images captured by a CCD camera or on confocal images (Zeiss LSM 510). The number of cells with immunofluorescence above background was counted by an investigator blinded to treatment conditions. c-Fos immunoreactivity was assessed using a rabbit antiserum (1:5000; Santa Cruz Biotechnology, Santa Cruz, CA), and an anti-tyrosine hydroxylase mouse monoclonal was used for double-labeling (1:1000; Chemicon). The immunoreactivity was visualized by the biotin-streptavidin technique (ABC kit; Vector) using 3,3'-diaminobenzidine and Vector SG as chromogens for c-Fos and $\mathrm{TH}$, respectively.

Double-labeling immunohistochemistry in situ hybridization. Striatal sections were immunolabeled for $\beta$-gal as described above except that detection was performed using biotin-conjugated secondary antibodies (Vector Laboratories). The sections were then incubated with ${ }^{35} \mathrm{~S}$ labeled probes complementary to exon 4 of rat prodynorphin, the cDNA of proenkephalin, or a $1.2 \mathrm{~kb}$ portion of the cDNA for CRF. The sections were then washed, dried, and dipped in NT2B emulsion (Eastman Kodak, Rochester, NY). Emulsions were developed 1-3 weeks later and counterstained with cresyl violet. Light- and dark-field microscope images of the NAc were captured at $20 \times$, and grains above background were counted in dark field using the Bioquant program quantification array. The light microscope image was then superimposed, and counts were grouped by coexpression of $\beta$-gal. Grain counts showed a bimodal distribution; cells in the upper peaks were designated as dynorphinergic or enkephalinergic. The proportion of the total number of $\beta$-gal-positive cells that also expressed prodynorphin or proenkephalin mRNA was then calculated.

\section{RESULTS}

\section{Acute morphine withdrawal increases CRE-mediated transcription in select brain areas}

As a preliminary experiment, we treated CRE-LacZ mice with a chronic escalating dose regimen of morphine and precipitated withdrawal with naltrexone. In mice receiving repeated saline or morphine injections alone, levels of immunoreactivity of the $\beta$-gal reporter were undetectable. Because levels of phosphoCREB can be detected in brain under basal conditions, the undetectable basal levels of $\beta$-gal expression observed in the CRE-LacZ mice presumably reflect a relatively low level of sensitivity of the reporter gene, a phenomenon observed in many transgenic reporter lines. Precipitation of withdrawal in chronic morphinetreated mice induced $\beta$-gal immunoreactivity in several brain areas, including the lateral septum, interstitial nucleus of the posterior limb of the anterior commissure (IPAC), central nucleus of the amygdala (CeA), and LC. This effect was quantified in the $\mathrm{CeA}$, where withdrawal induced $\beta$-gal immunoreactivity by $\sim 80 \%$ above controls that received chronic saline and an acute naltrexone injection (control, $107 \pm 32$ cells $/ \mathrm{mm}^{2}$; withdrawal, $195 \pm 51$ cells $/ \mathrm{mm}^{2} ; p<0.05$ by $t$ test; $n=5$ for each group).

\section{Regional mapping of CRE-mediated transcription in brain during opiate withdrawal}

The chronic injection schedule of morphine administration used in preliminary experiments produced relatively low levels of morphine dependence in the transgenic mice, based on the observation that very few overt behavioral symptoms of withdrawal were seen after naltrexone administration (Table 1). This is not unexpected given the intermittent nature of morphine exposure. Therefore, to induce a greater degree of morphine dependence, mice were implanted subcutaneously with either sham colloid or morphine pellets and then injected with naltrexone or saline. Morphine pellets induce a much greater degree of dependence because they provide continuous exposure to the drug (Rasmus- 


\begin{tabular}{lcc}
\hline \multicolumn{2}{l}{ Table 1. Behavioral indices of opiate withdrawal in CRE-LacZ mice } \\
Withdrawal sign & $\begin{array}{l}\text { Morphine injection } \\
\text { paradigm }\end{array}$ & $\begin{array}{l}\text { Morphine pellet } \\
\text { paradigm }\end{array}$ \\
\hline Jumps & $3.7 \pm 2.4$ & $43.3 \pm 8.5$ \\
Wet dog shakes & $5.7 \pm 0.7$ & $41.3 \pm 9.2$ \\
Body tremors & $3.3 \pm 0.7$ & $6.0 \pm 0$ \\
Paw tremors & $1.8 \pm 0.8$ & $28.8 \pm 2.9$ \\
Ptosis & $1.8 \pm 0.5$ & $6.0 \pm 0$ \\
Backward locomotion & $1.0 \pm 0.4$ & $3.5 \pm 1.9$ \\
Weight loss (\%) & $1.5 \pm 0.5$ & $3.0 \pm 0.3$
\end{tabular}

$\overline{\mathrm{CRE}-L a c Z \text { mice and their littermates without the transgene were scored for signs of }}$ opiate withdrawal for $30 \mathrm{~min}$ after a single naltrexone injection to animals that received chronic morphine injections or chronic morphine pellets. See Materials and Methods for a description of the drug treatments and scoring of withdrawal signs. Data are expressed as the mean \pm SEM $(n=4-6$ animals in each group). There was no difference in the expression of opiate withdrawal between mice with or without the transgene (data not shown). In addition, withdrawal symptoms in chronic morphine-treated animals (injections or pellets) given saline, and in chronic shamtreated animals given naltrexone, were either minimal or absent (data not shown).

sen et al., 1990). Indeed, as expected, mice implanted with morphine pellets showed a much more dramatic induction of classic withdrawal signs after naltrexone administration, including jumping, wet dog shakes, lacrimation, and diarrhea (see Table 1).

Based on these observations, we performed a general mapping (Table 2) of brain areas that show $\beta$-gal expression in four groups of transgenic mice ( $n=3$ for each group): control mice (sham pellets followed by saline injection); naltrexone control mice (sham pellets followed by naltrexone injection); chronic morphine mice (morphine pellets followed by saline injection); and withdrawal mice (morphine pellets followed by naltrexone injection). $\beta$-gal expression was virtually undetectable in the control mice. The naltrexone controls showed low to moderate levels of $\beta$-gal expression in many brain regions, including the septum, NAc, amygdala, the paraventricular, lateral, and dorsomedial hypothalamus, parasubthalamic nucleus, and lateral tegmental nucleus. Chronic morphine-treated mice also exhibited increased levels of $\beta$-gal immunoreactivity. In this group, $\beta$-gal expression was particularly evident in the lateral septum, dorsal striatum, lateral hypothalamus, superior colliculus, ventral periaqueductal gray, and brachial nuclei, with lower levels of induction apparent in numerous other brain areas such as NAc and LC. The precipitation of acute withdrawal in chronic morphine-treated mice caused more robust induction of CRE-mediated transcription in the same brain regions activated in the naltrexone control and chronic morphine-treated mice. The effect of withdrawal was most evident in the lateral septum, NAc, CeA, hypothalamus, and LC. Although most regions that showed changes in CRE-mediated transcription during morphine withdrawal exhibited increases in this measure, reductions were apparent in two brain areas: the lateral VTA and DRN (Table 2; and see below).

Our mapping study using coronal sections indicated that $\beta$-gal expression was increased in component regions of the neuroanatomical continuum known as the extended amygdala (Heimer et al., 1997) in all mice undergoing opiate withdrawal. Using horizontal sections of brains from withdrawing animals (Fig. 1) we were able to visualize $\beta$-gal expression throughout the lateral division of the extended amygdala. This division includes the NAc shell, bed nucleus of the stria terminalis, sublenticular extended amygdala, IPAC, and CeA. Naltrexone treatment alone induced lower levels of $\beta$-gal expression in most of these same brain regions.

\section{CRE-mediated transcription in the central nucleus of the amygdala during morphine withdrawal}

In the $\mathrm{CeA}$ there was a more than twofold increase in the number of cells expressing $\beta$-gal in mice undergoing opiate withdrawal compared with naltrexone controls (Fig. $2 C-E$ ). Moreover, this induction of $\mathrm{CRE}$ activity in the $\mathrm{CeA}$ was more than twice that observed with the escalating morphine injection paradigm (see above), consistent with the greater degree of opiate dependence and withdrawal induced by the morphine pelleting procedure. There was also a greater number of $\beta$-gal+ cells in the CeA of naltrexone control mice undergoing the sham pelleting procedure (Fig. 2E) compared with repeated saline injections (see above). This may be attributable to the larger dose of naltrexone used in the pelleted animals or to an increase in the tone of endogenous opioid systems caused by the increased stress of the pelleting procedure. In contrast to the $\mathrm{CeA}$, no induction of CRE-activity was observed in the basolateral nucleus of the amygdala.

To determine whether the induction of CRE-mediated transcription in the $\mathrm{CeA}$ was related to activity at the $\mu \mathrm{OR}$, double immunofluorescent labeling for $\beta$-gal and the $\mu \mathrm{OR}$ was performed and analyzed by confocal microscopy. In the naltrexone controls, $60 \pm 4 \%$ of $\beta$-gal + cells were found to express the $\mu \mathrm{OR}$ ( $n=3$ animals) (Fig. $3 A$ ). However, in the morphine withdrawal group, only $35 \pm 7 \%$ of the $\beta$-gal + cells coexpress the $\mu \mathrm{OR}(n=$ 3 animals) (Fig. $3 B$ ). We also examined whether CRE-mediated transcription occurred in neurons that express CRF (corticotropin-releasing factor), a major neuropeptide in the CeA (Fig. 3C). Using a double-labeling immunohistochemistry in situ hybridization procedure, it was found that during morphine withdrawal $34 \pm 9 \%$ ( $n=3$ animals $)$ of the $\beta$-gal + cells were strongly labeled for CRF in this region. This represented $\sim 50 \%$ of the CRF cells observed. Minimal colocalization of $\beta$-gal immunoreactivity and CRF mRNA was apparent in naltrexone control mice $(n=3$ animals $)$.

\section{CRE-mediated transcription in the nucleus accumbens during morphine withdrawal}

Robust increases in the number of $\beta$-gal + cells were observed in both the core and shell divisions of the NAc in mice undergoing morphine withdrawal (Fig. $2 A, B, E$ ). The induction was fourfold in the core and twofold in the shell, compared with naltrexone controls. As with the CeA, moderate levels of $\beta$-gal expression were observed in the shell, but not the core, of naltrexone control mice.

The chemical phenotype of the cells expressing $\beta$-gal in the NAc was determined by double-labeling techniques, either immunohistochemistry in situ hybridization or double-labeling immunohistofluorescence (see Materials and Methods). Proenkephalin and prodynorphin expression defines two major subsets of medium spiny projection neurons in the NAc, which together account for $>90 \%$ of the neurons in this region. Double-labeled cells represented $\sim 10 \%$ of the total dynorphinergic and total enkephalinergic populations sampled. In animals undergoing morphine withdrawal, it was determined that $18 \pm 2 \%$ of the $\beta$-gal + cells coexpressed proenkephalin mRNA $(n=3$ animals $)$ (Fig. $4 A$ ), whereas $24 \pm 2 \%$ expressed prodynorphin mRNA $(n=$ 3 animals) (Fig. $4 B$ ). $\beta$-gal immunoreactivity in withdrawal animals also colocalized with calbindin $(31 \pm 6 \% ; n=3$ animals $)$ (Fig. 4C), a marker for a subclass of GABAergic interneurons in 
Table 2. Regulation of CRE-mediated transcription in brain by chronic morphine, naltrexone, and morphine withdrawal

\begin{tabular}{|c|c|c|c|c|}
\hline Region & Control & Morphine & Naltrexone & Withdrawal \\
\hline $\begin{array}{l}\text { Cortex } \\
\text { Motor }\end{array}$ & + & ++ & + & ++ \\
\hline \multicolumn{5}{|l|}{ Septum } \\
\hline Medial & 0 & 0 & 0 & ++ \\
\hline Lateral & + & ++ & + & +++ \\
\hline Dorsal striatum & 0 & ++ & + & ++ \\
\hline \multicolumn{5}{|l|}{ Nucleus accumbens } \\
\hline Core & 0 & + & + & +++ \\
\hline Shell & 0 & + & ++ & +++ \\
\hline IPAC & 0 & + & ++ & ++++ \\
\hline \multicolumn{5}{|l|}{ BST } \\
\hline Medial & 0 & + & + & + \\
\hline Lateral & 0 & 0 & ++ & ++++ \\
\hline \multicolumn{5}{|l|}{ Amygdala } \\
\hline Basolateral & 0 & + & + & + \\
\hline Central & + & + & +++ & +++++ \\
\hline Basomedial & + & + & + & + \\
\hline Lateral habenula & 0 & 0 & + & ++ \\
\hline \multicolumn{5}{|l|}{ Hypothalamus } \\
\hline Lateral & + & ++ & + & +++ \\
\hline Paraventricular & + & + & ++ & +++ \\
\hline Anterior & 0 & + & + & ++ \\
\hline Suprachiasmatic & 0 & + & + & ++ \\
\hline Dorsomedial & 0 & + & ++ & ++++ \\
\hline Ventromedial & 0 & + & + & ++ \\
\hline Arcuate & + & + & + & ++ \\
\hline Posterior & 0 & + & + & ++ \\
\hline Preoptic area & + & 0 & + & ++ \\
\hline \multicolumn{5}{|l|}{ Thalamus } \\
\hline Paraventricular & + & 0 & ++ & ++ \\
\hline Mediodorsal & 0 & + & ++ & +++ \\
\hline Centromedial/reuniens & 0 & + & 0 & ++ \\
\hline Posterior & 0 & 0 & + & ++ \\
\hline \multicolumn{5}{|l|}{ Hippocampus } \\
\hline CA1 & + & + & + & ++ \\
\hline CA2 & 0 & 0 & 0 & + \\
\hline CA3 & + & + & + & ++ \\
\hline DG & 0 & + & + & + \\
\hline Zona incerta & + & + & + & ++ \\
\hline Substantia nigra & 0 & 0 & + & ++ \\
\hline Parasubthalamic nucleus & + & + & ++ & +++ \\
\hline \multicolumn{5}{|l|}{ VTA } \\
\hline Lateral & + & + & + & $+/-$ \\
\hline Medial & 0 & + & + & $+/++$ \\
\hline Geniculate nucleus & 0 & ++ & ++ & ++ \\
\hline Superior colliculus & + & ++ & + & ++ \\
\hline Periaqueductal gray & 0 & + & + & ++ \\
\hline Dorsal raphe & + & + & + & $+/-$ \\
\hline Lateral tegmental nucleus & 0 & + & ++ & +++ \\
\hline Dorsal tegmental nucleus & 0 & 0 & 0 & 0 \\
\hline Locus coeruleus & 0 & + & + & ++ \\
\hline Central gray & 0 & 0 & + & ++ \\
\hline Parabrachial and subbrachial nuclei & 0 & ++ & + & ++ \\
\hline Pontine nucleus & + & + & + & ++ \\
\hline
\end{tabular}

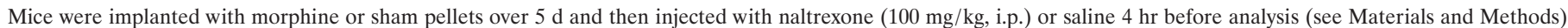

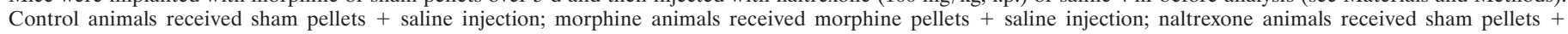

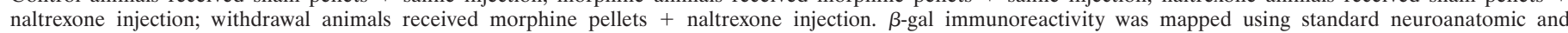

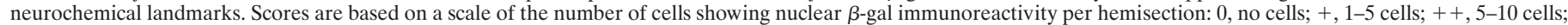
,$+++ 10-20$ cells;,$++++ 20-40$ cells;,$+++++>40$ cells. The mean score for three animals from each group is presented. 


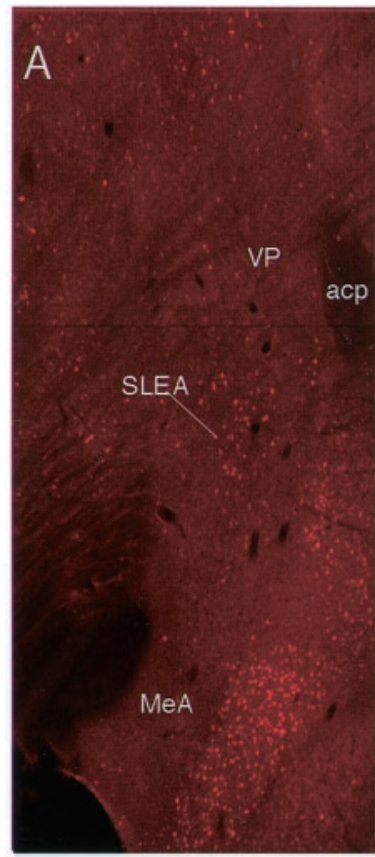

Naltrexone
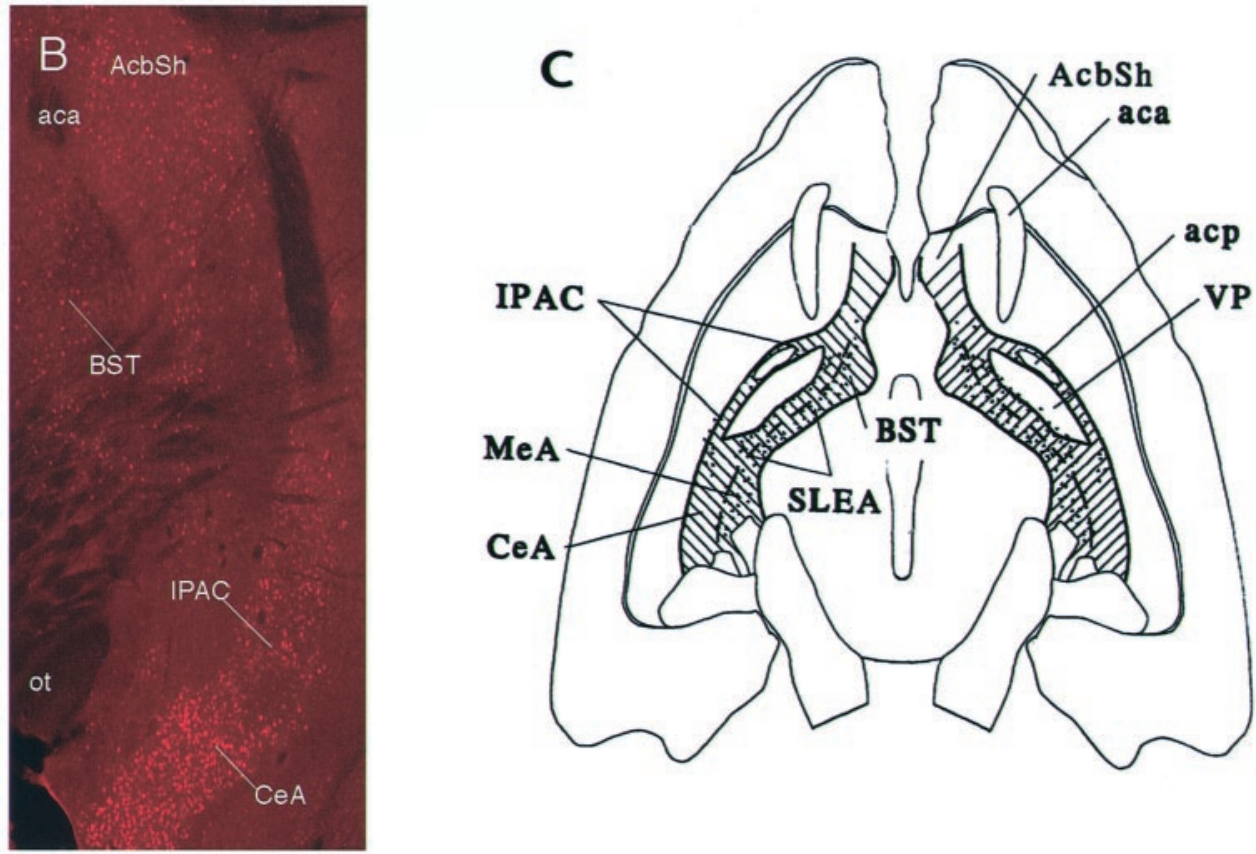

Figure 1. CRE-mediated transcription is induced in the extended amygdala during morphine withdrawal. Horizontal sections through brain were obtained from naltrexone control mice $(A)$ and mice experiencing acute withdrawal $(B)$ and then immunostained for $\beta$-gal. $C$, Diagram of component regions of the extended amygdala [from Heimer and Alheid (1991)]. aca, Anterior limb of anterior comissure; $a c p$, posterior limb of anterior commissure; $B S T$, bed nucleus of the stria terminalis; $C e A$, central nucleus of the amygdala; $I P A C$, interstitial nucleus of the posterior limb of the anterior commissure; $A c b S h$, nucleus accumbens shell; $O T$, optic tract; $S L E A$, sublenticular extended amygdala; $V P$, ventral pallidum.

the NAc. In contrast, there was virtually no colocalization of $\beta$-gal expression with choline acetyltransferase (a marker for cholinergic interneurons; $3 \pm 3 \% ; n=3$ animals) (Fig. $4 D$ ), parvalbumin (a marker for another class of GABAergic interneurons; $2 \pm$ $2 \% ; n=3$ animals) (Fig. $4 E$ ), or S-100 (a glial and ependymal cell marker; $4 \pm 4 \% ; n=3$ animals) (Fig. $4 F$ ). In naltrexone control mice, $\beta$-gal expression was also observed in both subtypes of medium spiny neurons in the NAc, although the total number of $\beta$-gal + cells was too low to perform quantitation ( $n=3$ animals). These data show that the CRE-mediated transcription induced in the NAc during opiate withdrawal occurs in a mixed population of neurons, including both major subtypes of medium spiny neurons and one subset of interneuron.

\section{CRE-mediated transcription in the LC during morphine withdrawal}

Precipitation of morphine withdrawal increased the number of $\beta$-gal+ cells in the LC twofold relative to naltrexone controls. Confocal microscopy of sections double-labeled for $\beta$-gal and $\mathrm{TH}$ revealed $\beta$-gal expression in both $\mathrm{TH}$ and non-TH expressing cells in the withdrawal and naltrexone groups (Fig. 5I-L). The bulk of the $\beta$-gal $+/ \mathrm{TH}$ - cells were located on the perimeter of the LC nucleus, and only those cells intimately associated with the nucleus were included in the analysis. TH is the rate-limiting enzyme in catecholamine biosynthesis and therefore marks the noradrenergic neurons in this brain region. Interestingly, $69 \pm$ $10 \%$ of the $\beta$-gal + cells in the withdrawal group ( $n=5$ animals $)$ were $\mathrm{TH}+($ Fig. $6 C$ ). In the naltrexone controls $(n=3)$, a smaller proportion $(54 \pm 15 \%)$ of $\beta$-gal-expressing cells were $\mathrm{TH}+($ Fig. $6 I$ ). These findings suggest that the induction of CRE-mediated transcription in the LC during opiate withdrawal occurs predom- inantly in $\mathrm{TH}+$ cells, with some induction occurring in non-TH populations as well.

\section{CRE-mediated transcription in the ventral tegmental area and dorsal raphe nucleus during morphine withdrawal}

The VTA of the midbrain contains dopaminergic neurons, which project to the NAc and other forebrain regions, and are important substrates for the rewarding actions of opiates and other drugs of abuse (Koob, 1999). In this region, levels of $\beta$-gal expression in naltrexone control animals were low compared with many other brain areas. Even so, quantitation revealed a reduction in the number of $\beta$-gal + cells in mice undergoing morphine withdrawal compared with the naltrexone controls (Fig. $5 A-D$ ). This effect was more apparent in the lateral VTA than in the medial subdivision of this nucleus. When the phenotype of $\beta$-gal-expressing cells in the VTA was analyzed by confocal microscopy and double-labeling immunohistofluorescence, we found that a large majority $(79 \pm 6 \%)$ of $\beta$-gal + cells sampled in the naltrexone controls ( $n=5$ animals) were $\mathrm{TH}+$ (Fig. $6 G)$, whereas a much smaller number $(21 \pm 5 \%)$ of $\beta$-gal + cells in the withdrawal group ( $n=5$ animals) were $\mathrm{TH}+$ (Fig. $6 A$ ). These data suggest that the reduction in CRE-mediated transcription observed during morphine withdrawal in the VTA occurs preferentially in the TH-expressing dopaminergic neurons of this brain region. In addition, CRE-mediated transcription may increase in the nondopaminergic population of the VTA, particularly in its medial extent.

In the DRN, a major serotonergic nucleus in brain, there also was a significant reduction in the number of $\beta$-gal + cells observed during morphine withdrawal compared with naltrexone controls 
NUC. ACCUMBENS
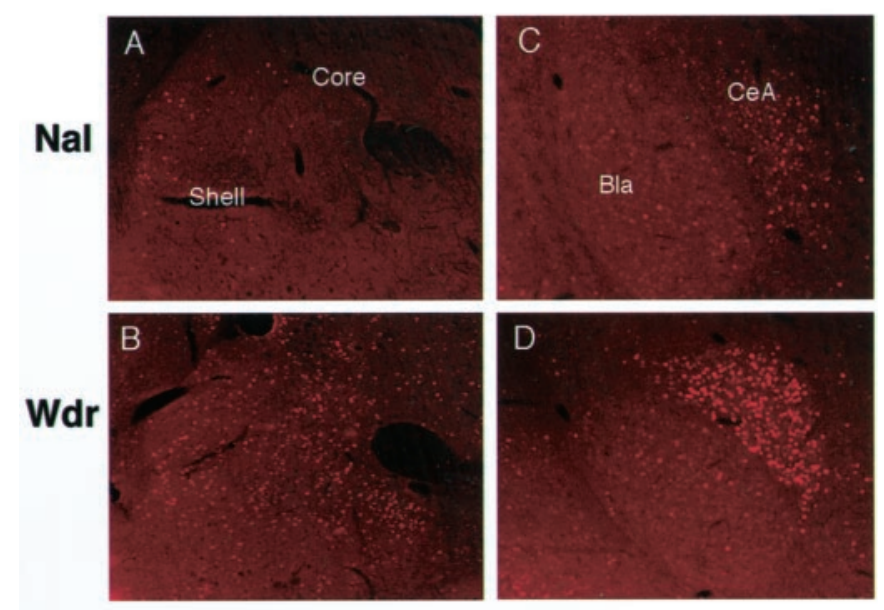

D

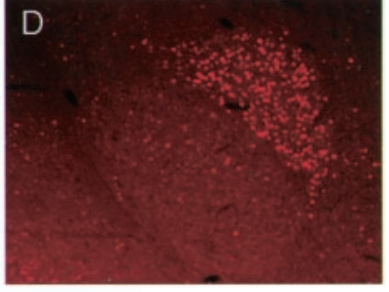

E

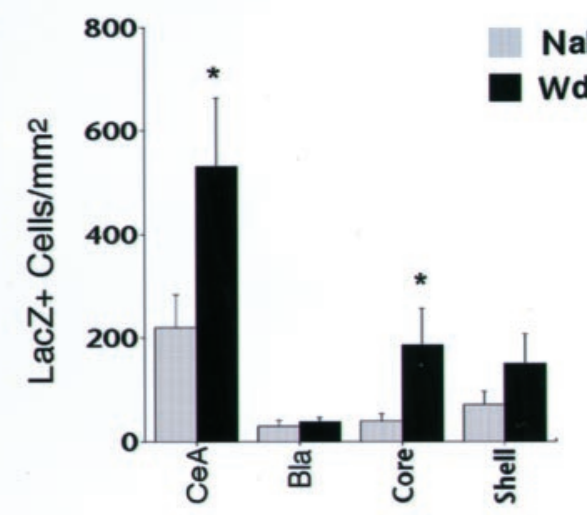

Region
Figure 2. CRE-mediated transcription is induced in the nucleus accumbens core and the central nucleus of the amygdala during morphine withdrawal. Mice received sham $(A, C)$ or morphine $(B, D)$ pellets over $5 \mathrm{~d}$ followed by naltrexone. The number of cells expressing $\beta$-gal was counted for two hemisections (at $10 \times$ ) per animal between bregma +1.54 and +0.98 for the NAc core and shell regions $(A, B)$ and for three hemisections (at $20 \times$ ) between bregma -0.82 and -1.94 for the CeA and the basolateral nucleus of the amygdala $(B l a)(C, D)$. The induction observed in the NAc core $(n=9$ animals; $p<0.05$ by $t$ test $)$ and in the central nucleus of the amygdala $(n=10$ animals; $p<0.05)$ was significant, whereas there was a trend for an induction in the NAc shell $(p<0.1 ; n=$ 9 animals). Nal, Naltrexone controls; $W d r$, withdrawal mice.

(Fig. 5E-H). Serotonin immunoreactivity was used as a marker for serotonergic neurons in this brain region for double-labeling immunofluorescence studies. In naltrexone control mice $(n=3$ animals), approximately half $(49 \pm 5 \%)$ of $\beta$-gal + cells were serotonergic (Fig. $6 B$ ), whereas in the withdrawal group $(n=3)$ the proportion of $\beta$-gal + cells that were serotonergic was reduced (24 $\pm 16 \% ; n=3$ animals) (Fig. $6 H$ ). It appears, then, that the reduction in CRE-mediated transcription seen in the DRN during withdrawal is taking place largely in the serotonergic neurons located in this brain region.

\section{c-Fos expression in monoaminergic nuclei during morphine withdrawal}

To further examine the subtype of cells in monoaminergic nuclei that are regulated during morphine withdrawal, we analyzed
c-Fos immunoreactivity $2 \mathrm{hr}$ after naltrexone injection in morphine-dependent mice. c-Fos, like CREB activation, has been used as a marker of neuronal activity in many experimental paradigms (Morgan and Curran, 1995), including opiate withdrawal (Hayward et al., 1990). However, there are some differences in the intracellular signaling pathways that control c-Fos expression and CRE-mediated transcription, which makes the comparison of the two phenomena of particular interest. In the LC, c-Fos induction was observed predominantly in $\mathrm{TH}$ expressing cells, but also in a smaller number of non-TH expressing cells (located especially in the periphery of this nucleus), consistent with our observations of CRE-mediated activity (Fig. $6 F$ ). In the VTA and DRN, c-Fos was found virtually exclusively in non-TH cells (VTA) (Fig. 6D) and nonserotoninergic cells (DRN) (Fig. 6E), respectively, during withdrawal. Thus, the cellular pattern of c-Fos expression in these three monoaminergic nuclei during opiate withdrawal in general corresponds to the regulation of CRE-mediated transcription observed within these brain regions. The main divergence in the two measures was the observation of some serotonergic cells that were CRE+ but no detectable serotonergic cells that were c-Fos + . The mechanisms responsible for this differential regulation remain unknown.

\section{DISCUSSION}

CRE-mediated transcription represents a critical node in the integrative function of a cell. It is a marker of the activation of several intracellular signaling cascades and of neurons undergoing synaptic plasticity through gene regulation. This study maps brain regions that show altered levels of CRE-mediated transcription during morphine withdrawal, which include areas implicated in the somatic symptoms of withdrawal, as well as in the rewarding properties of drugs of abuse and the aversive emotional symptoms that occur in drug withdrawal states (Maldonado et al., 1992; Koob, 1999). We have also identified specific neuronal cell populations in which these changes occur and characterized them in terms of particular genes whose expression may be regulated by activity at their CRE sites during withdrawal. These changes in CRE-mediated transcription serve as a functional marker for homeostatic neuronal adaptations and for synaptic plasticity occurring during withdrawal as a consequence of chronic opiate exposure.

\section{CRE-mediated transcription in the LC: confirmation of a molecular model of opiate dependence}

Activation of LC noradrenergic neurons during withdrawal mediates some of the somatic symptoms of the withdrawal syndrome (Maldonado et al., 1992; Nestler and Aghajanian, 1997). There is considerable evidence to support the view that this activation is mediated partly by an upregulated cAMP signaling pathway that occurs in these neurons during chronic opiate exposure (Nestler and Aghajanian, 1997). We had previously shown that acute morphine administration reduces CREB phosphorylation in the LC, that this reduction resolves during chronic morphine exposure, and that it increases dramatically after precipitation of withdrawal (Guitart et al., 1992). Results of the present study are consistent with these earlier observations as there is a modest induction of CRE activity in the LC in morphine-dependent animals and a robust induction during withdrawal. This pattern of regulation supports the view that the full functional consequences of the upregulated cAMP pathway become apparent only when the per- 
Naltrexone

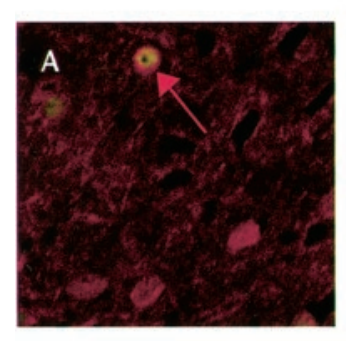

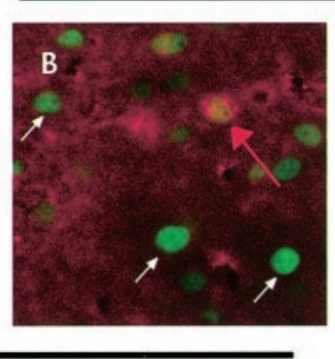

MOR

\section{Withdrawal}

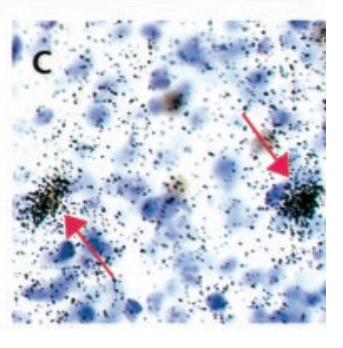

CRF

Figure 3. CRE-mediated transcription occurs in $\mu \mathrm{OR}$ and $\mathrm{CRF}$ expressing cells of the central nucleus of the amygdala. Cellular colocalization of $\beta$-gal immunoreactivity (nuclear, green) and $\mu \mathrm{OR}$ immunoreactivity (cell body, red) was determined by confocal microscopy in sections from naltrexone controls $(A)$ and withdrawal animals $(B)$ (red arrows indicate colocalization, white arrows indicate cells not expressing the $\mu \mathrm{OR})$. Double-labeling for $\beta$-gal immunoreactivity and for CRF mRNA demonstrates a high degree of colocalization in this brain region during withdrawal $(C)$. Results are representative of the following mean number of $\beta$-gal + cells counted in each of three or four animals: 28 cell per animal for $\mu \mathrm{OR}$ under naltrexone conditions; 33 cells per animal for $\mu \mathrm{OR}$ under withdrawal conditions; and 45 cells per animal for CRF under withdrawal conditions.

sistent inhibitory effects of opiates are removed. The induction of CRE activity that occurs during withdrawal appears to occur predominantly in $\mathrm{TH}+$ neurons of the LC, consistent with previous evidence for transcriptional regulation of these neurons by chronic morphine treatment (Lane-Ladd et al., 1997; Boundy et al., 1998). However, it is also clear that CRE transcription is activated during withdrawal in non-TH cells that are intimately associated with the LC. Neuroadaptations in this population may be responsible for some aspects of withdrawal that are still observed when the noradrenergic neurons of the LC are neurochemically lesioned (Christie et al., 1997; Caille et al., 1999).

\section{CRE-mediated transcription in the VTA and DRN: inhibition of monoaminergic cells}

In contrast to the LC, we found a reduction in CRE activity in the lateral VTA during opiate withdrawal, which appeared to occur selectively in dopaminergic neurons. Chronic morphine decreases the size of VTA dopaminergic neurons (SklairTavron et al., 1996), and electrophysiologic and microdialysis studies indicate reduced dopaminergic activity during withdrawal (Diana et al., 1995, 1999, Rosetti et al., 1992). VTA dopaminergic neurons may be inhibited during withdrawal by rebound GABAergic transmission by local interneurons whose cAMP pathway has been upregulated by chronic morphine (Bonci and Williams, 1997; Williams et al., 2001). In the medial VTA, we did observe a small increase in CRE-mediated transcription during withdrawal (Table 1), which would be consistent with this model. The induction of c-Fos in nondopaminergic cells during opiate withdrawal further supports the occurrence of adaptations in these neurons as a consequence of chronic opiate administration. The observed differences between lateral and medial aspects of the VTA underscore the need to better understand functional heterogeneity within this nucleus.

The actions of morphine in the DRN generally parallel observations in the VTA. Chronic morphine upregulates the cAMP pathway in nonserotonergic cells of this region, and during withdrawal the firing of serotonergic neurons is decreased secondary to increased GABAergic transmission (Jolas et al., 2000). This reduction in serotonergic function could contribute to the somatic and emotional symptoms of the withdrawal syndrome. Consistent with the notion that the nonserotonergic cells are sensitive to morphine, induction of CRE-transcription and c-Fos expression during withdrawal occurs predominantly in this cell population. Moreover, there appears to be a reduction in CRE activity in the serotonergic cells of this nucleus during withdrawal, although a small number of serotonergic cells still show CRE-mediated transcription.

\section{CRE-mediated transcription in the extended amygdala: systems and cellular specificity of activation}

This study provides a novel topographical view of the extended amygdala at the functional level as a distributed telencephalic superstructure in which endogenous opioid peptide systems exert a tonic inhibitory effect on CRE activity. The extended amygdala is an anatomic conglomerate of neurochemically similar structures in the basal forebrain that are thought to integrate the affective state of an individual in relation to endocrine, autonomic, and somatosensory information (Heimer et al., 1997). CRE-mediated transcription during naltrexone-precipitated opi-
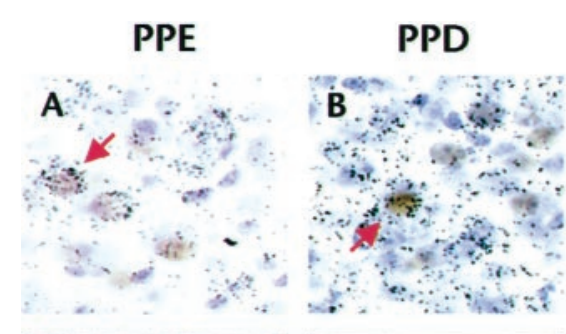

\section{Calbindin}

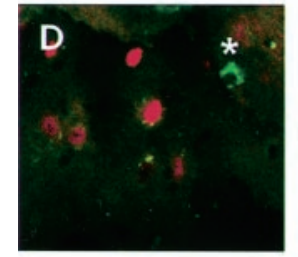

ChAT

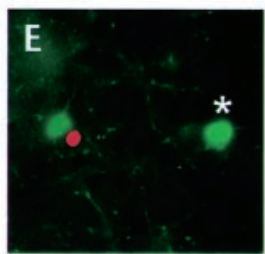

Parvalbumin
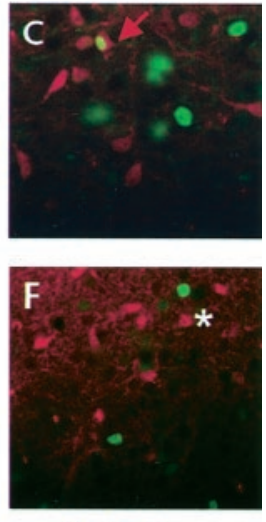

S-100
Figure 4. CRE-mediated transcription is induced in projection neurons and interneurons in the nucleus accumbens during morphine withdrawal. Double-labeling for $\beta$-gal immunoreactivity and for preproenkephalin $(P P E)(A)$ and preprodynorphin $(P P D)(B)$ mRNA revealed prominent colocalization of $\beta$-gal with both neuropeptides in mice undergoing withdrawal (arrows indicate double-labeled cells, $60 \times$ ). $C$, Confocal images of double immunofluorescently labeled sections from mice in withdrawal revealed considerable cellular colocalization between $\beta$-gal (green, nuclear, $20 \times$ ) and the interneuron marker calbindin (red, cytoplasmic, confocal image $20 \times$ ). In contrast, no colocalization was observed between $\beta$-gal (green, nuclear) and markers of two other interneurons, choline acetyltransferase (ChAT) (D, green, cytoplasmic, 20×; asterisk indicates cholinergic interneuron) and parvalbumin ( $E$, green, cytoplasmic, 60×; asterisk indicates parvalbumin + interneuron). $\beta$-gal immunoreactivity also did not colocalize with the glial marker S-100 ( F, red, cytoplasmic, $20 \times$; asterisk indicates glial cell). Results are representative of the following mean number of $\beta$-gal+ cells counted in each of three animals: 28 cells per animal for PPE; 24 cells per animal for PPD; 45 cells per animal for calbindin; 13 cells per animal for ChAT; 14 cells per animal for parvalbumin; and 11 cells per animal for S-100. 

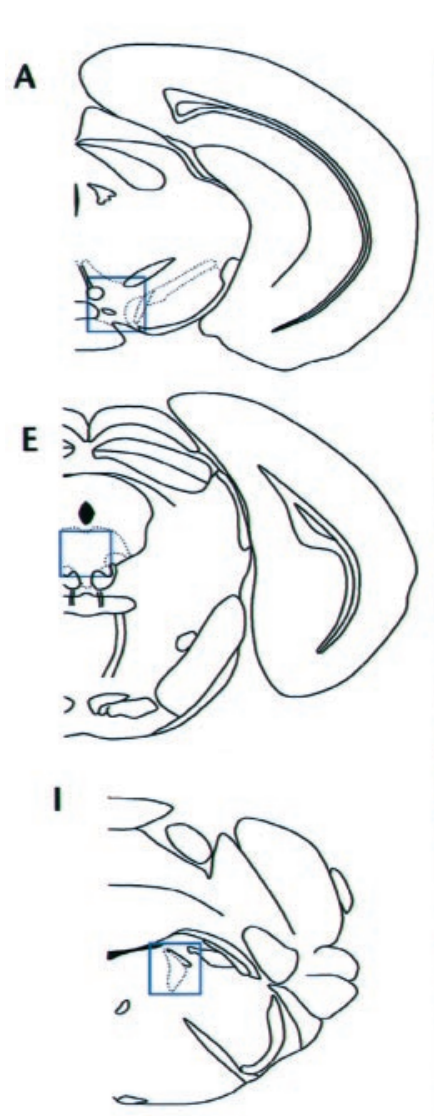

Naltrexone
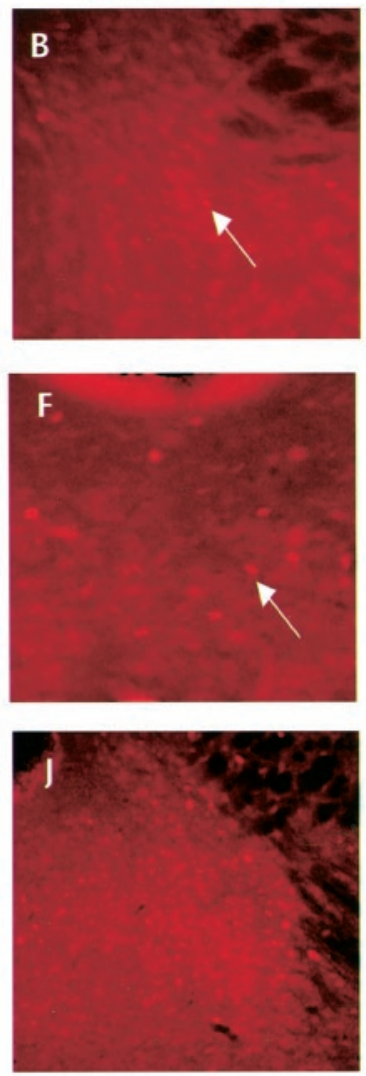

Withdrawal
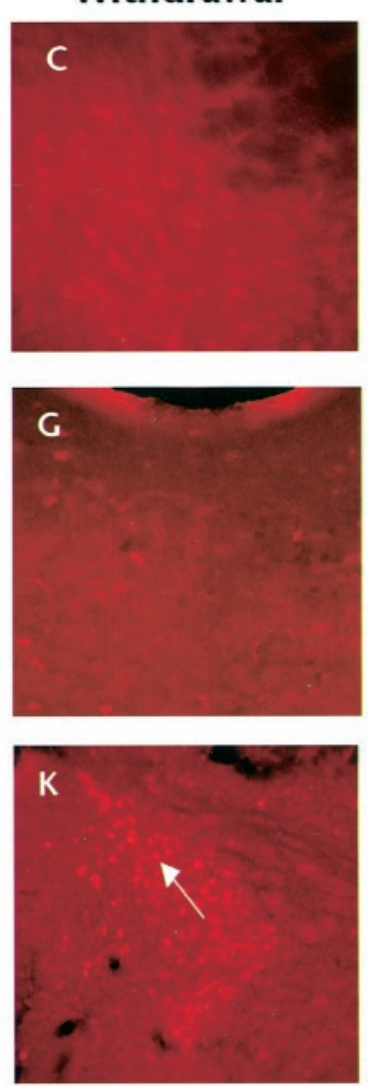
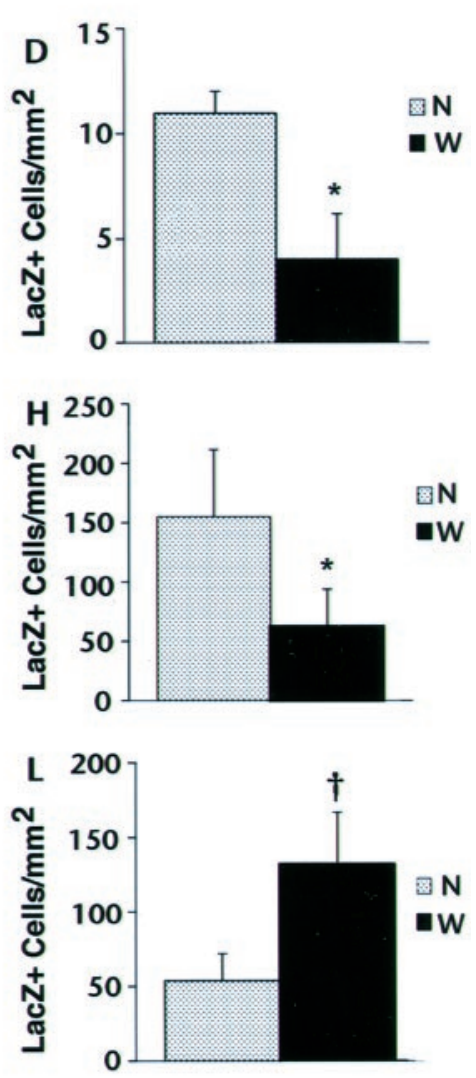

Figure 5. CRE-mediated transcription is altered in monoaminergic nuclei during morphine withdrawal. Mice received morphine or sham pellets over $5 \mathrm{~d}$ followed by naltrexone. The number of cells expressing $\beta$-gal was counted for each region on two to four hemisections in withdrawal mice $(C$, $G$, $K)$ and naltrexone controls $(B, F, J)$. Arrows indicate one example of a $\beta$-gal + cell in $(B, F, K)$. For the VTA $(A-D)$ and LC $(I-L)$, quantitation focused on areas that stained for tyrosine hydroxylase at bregma levels -3.16 and $-5.40 \mathrm{~mm}$, respectively (areas highlighted by blue box in $A$ and $I$ ). For the DRN $(E-H)$, quantitation focused on the B6 and B7 regions at bregma level $-4.36 \mathrm{~mm}$, which showed staining for serotonin (area highlighted by blue box in $E)$. There was a significant decrease in the number of $\beta$-gal + cells per unit area in both the VTA $(D)$ and the DRN $(H)$ in mice undergoing withdrawal compared with naltrexone controls $(n=8-10$ animals in each group; $p<0.05$ by $t$ test). There was a strong trend for an increase in the number of $\beta$-gal + cells per unit area in the LC $(L)$ in the withdrawal group compared with naltrexone controls $(n=10$ for each group; $p<0.09)$.

ate withdrawal essentially defines the lateral division of this anatomic continuum.

Induction of CRE activity in the CeA, which is part of this lateral division, is consistent with previous observations that chronic morphine administration upregulates the cAMP pathway in this nucleus (Terwilliger et al., 1991). The CeA has been associated with aversive emotional states such as fear (Davis, 1998; LeDoux, 2000), and in the context of addiction with the dysphoria that occurs during early phases of drug withdrawal (Koob, 1999). It also is important for stimulus-reward learning (Robbins and Everitt, 1996). Here, we describe the cellular specificity of CRE activity in the CeA during morphine withdrawal. Naltrexone administration to morphine-naive mice induced a low level of CRE-mediated transcription in the CeA that occurs mainly in $\mu \mathrm{OR}$-expressing cells. The most straightforward explanation of these data are that naltrexone, in morphine-naive animals, reverses a tonic inhibitory effect exerted by endogenous opioid peptides acting on $\mu \mathrm{OR}$ signaling pathways (e.g., the cAMP pathway) that regulate CREB activity. Indeed, the regional pattern of CRE activity seen under these conditions is similar to the distribution of $\mu \mathrm{OR}$ expression in brain (Mansour et al., 1995).
In contrast, the large majority of cells that show CRE activity in CeA during morphine withdrawal do not express the $\mu \mathrm{OR}$. CRE transcription in this population may reflect the induction of synaptic plasticity secondary to altered neurotransmission during withdrawal. We show that this population of cells includes CRFcontaining neurons. CRF neurotransmission in amygdala is implicated in the formation of conditioned associations with the aversive component of morphine withdrawal (Heinrichs et al., 1995). The CRF gene contains a CRE site in its promoter (Spengler et al., 1992), and its transcription is increased by PKA activation in cultured amygdala neurons (Kasckow et al., 1997). These observations raise the possibility that CRE-mediated regulation of CRF expression may contribute to the associative neuronal plasticity of opiate withdrawal.

\section{CRE-mediated transcription in the nucleus accumbens: role in addiction}

The NAc is a critical neural substrate for the rewarding properties of opiates and most other drugs of abuse (Koob, 1999). Chronic morphine or cocaine treatment upregulates the cAMP pathway within this brain region (Terwilliger et al., 1991; Unterwald et al., 1993). Chronic exposure to amphetamine 


\section{Withdrawal}
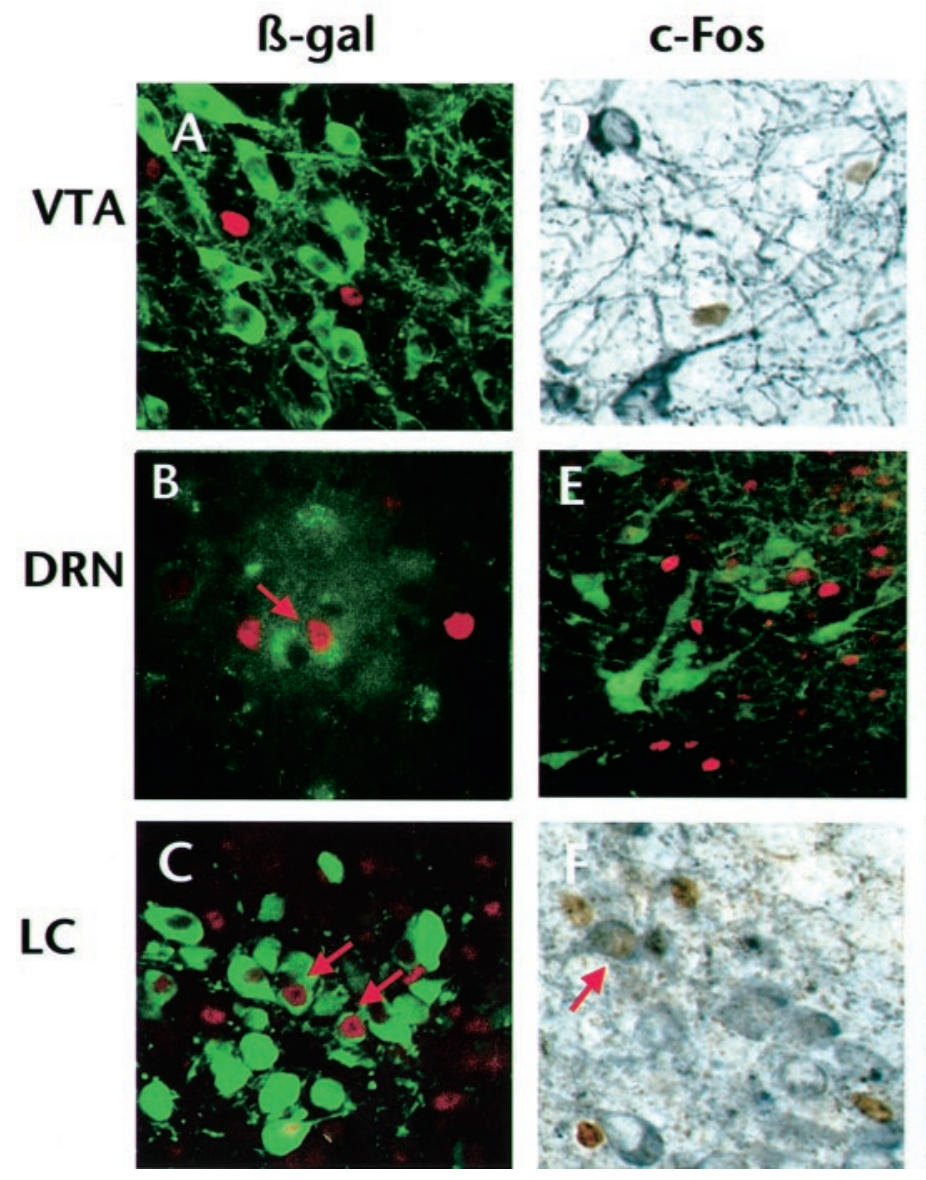
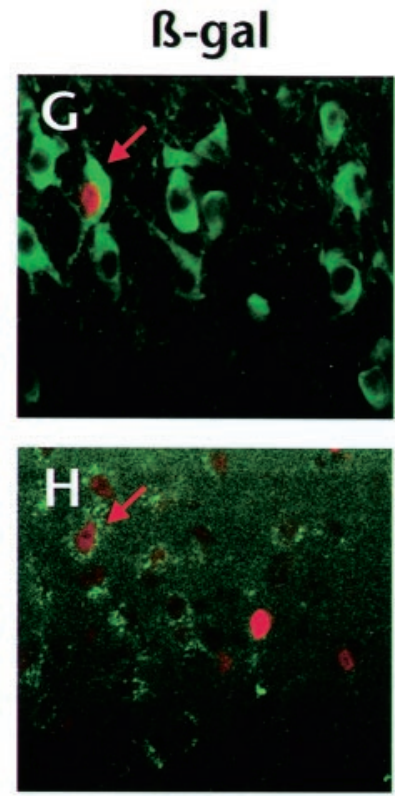

Naltrexone

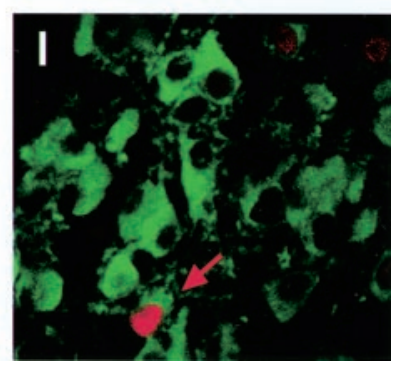

Figure 6. Cellular mapping of CREmediated transcription and c-Fos in the three major monoaminergic nuclei during morphine withdrawal. Cellular colocalization of $\beta$-gal immunoreactivity (nuclear, red; $A-C, G-I$ ) and TH (cytoplasmic, green; $A, C, G, I$ ) or serotonin (cytoplasmic, green; $B, E, H$ ) was assessed by Z-sectioning of confocal images at $60 \times$ in the lateral ventral tegmental area $(V T A ; A, G)$, the B6-B7 dorsal raphe nucleus $(D R N$; $B, H)$, and the locus ceruleus $(L C ; C, I)$ from CRE-LacZ withdrawal mice $(A-C)$ and naltrexone controls $(G-I)$. c-Fos immunoreactivity (nuclear) was also mapped in these nuclei during withdrawal $(D, E, F)$. Results shown in $A-C$ and $G-I$ are representative of the following mean number of $\beta$-gal+ cells counted in each of three to five animals: 9 VTA cells per animal under naltrexone conditions and 10 under withdrawal conditions; 21 DRN cells per animal under naltrexone conditions and 17 under withdrawal conditions; and 33 LC cells per animal under naltrexone conditions and 38 under withdrawal conditions. Results shown in $D-F$ are representative of the analysis of three to five animals in each group. increases the state of phosphorylation of CREB in striatal regions (Cole et al., 1995; Turgeon et al., 1997). Using viral vectors to overexpress $\mathrm{CREB}$, we have shown that increased CREB activity in the NAc reduces the rewarding properties of morphine and of cocaine (Carlezon et al., 1998; Barrot et al., 2000). Increased CREB function in this region also produces a negative emotional state as inferred from an animal model of depression (Pliakas et al., 2001). Together, these data support the scheme that observed induction of CRE-mediated transcription in the NAc may mediate tolerance to the rewarding effects of morphine and contribute, as with the CeA, to aversive aspects of the withdrawal syndrome (Nestler, 2001).

Induction of CRE activity in NAc during morphine withdrawal occurs in several subpopulations of neurons within this region, including both dynorphinergic and enkephalinergic projection neurons and one subtype of interneuron. Chronic morphine reduces expression of prodynorphin, proenkephalin, and protachykinin mRNA in this region (Georges et al., 1999). The expression of these transcripts normalizes after a few days of spontaneous withdrawal. As a primary regulator of prodynorphin and proenkephalin expression in cultured striatal neurons (Cole et al., 1995; Konradi et al., 1995), CREB acting via CRE sites present within the promoter regions of these genes may provide the homeostatic mechanism to normalize striatal neuropeptide expression.

\section{CRE-mediated transcription: resetting the homeostatic set point of gene expression}

Drug addiction can be viewed as a maladaptive process in which the neurobiologic systems responsible for reward, motivation, mood, and arousal undergo changes beyond the ability of the system to return to its original set point (Koob and Le Moal, 2001). We presented here a view of the global changes in cellular CRE transcriptional responses that occur as a consequence of chronic opiate exposure and withdrawal. The induction of CREmediated transcription during withdrawal, which is specific to particular neural circuits, provides both a mechanism of longlasting plasticity associated with the withdrawal experience, as well as a homeostatic mechanism that may reverse some adaptations that occur during chronic opiate exposure. Overall, regulation of CRE-mediated transcription could contribute to the functional transition to a new molecular set point during the addiction process.

\section{REFERENCES}

Barrot M, Olivier JDA, Zachariou V, Neve RL, Nestler EJ (2000) Influence of CREB in the nucleus accumbens shell on the sensitivity to aversive and nociceptive stimuli. Soc Neurosci Abstr 26:485.

Berke JD, Hyman SE (2000) Addiction, dopamine, and the molecular mechanisms of memory. Neuron 25:515-532.

Bonci A, Williams JT (1997) Increased probability of GABA release during withdrawal from morphine. J Neurosci 17:796-803. 
Boundy VA, Gold SJ, Messer CJ, Chen J, Son JH, Joh TH, Nestler EJ (1998) Regulation of tyrosine hydroxylase promoter activity by chronic morphine in TH9.0-LacZ transgenic mice. J Neurosci 18:9989-9995.

Caille S, Espejo E, Reneric JP, Cador M, Koob F, Stinus L (1999) Total neurochemical lesion of noradrenergic neurons of the locus ceruleus does not alter either naloxone-precipitated or spontaneous opiate withdrawal nor does it influence the ability of clonidine to reverse opiate withdrawal. J Pharmacol Exp Ther 290:881-892.

Carlezon Jr WA, Thome J, Olson VG, Lane-Ladd SB, Brodkin ES, Hiroi N, Duman RS, Neve RL, Nestler EJ (1998) Regulation of cocaine reward by CREB. Science 18:2272-2275.

Christie MJ, Williams JT, Osborne P, Bellchambers C (1997) Where is the locus in opioid withdrawal? Trends Pharmacol Sci 18:134-140.

Cole R, Konradi C, Douglass J, Hyman S (1995) Neuronal adaptations to amphetamine and dopamine: Molecular mechanisms of prodynorphin gene regulation in rat striatum. Neuron 14:813-823.

Davis M (1998) Are different parts of the extended amygdala involved in fear versus anxiety? Biol Psychiatry 44:1239-1247.

Diana M, Pistis M, Muntoni A, Gessa G (1995) Profound decrease of mesolimbic dopaminergic neuronal activity in morphine withdrawn rats. J Pharmacol Exp Ther 272:781-785.

Diana M, Muntoni AL, Pistis M, Melis M, Gessa G (1999) Lasting reduction in mesolimbic dopamine neuronal activity after morphine withdrawal. Eur J Neurosci 11:1037-1041.

Duman RS, Tallman JF, Nestler EJ (1988) Acute and chronic opiate regulation of adenylate cyclase in brain: specific effects in locus coeruleus. J Pharmacol Exp Ther 246:1033-1039.

Georges F, Stinus L, Bloch B, Le Moine C (1999) Chronic morphine exposure and spontaneous withdrawal are associated with modifications of dopamine receptor and neuropeptide gene expression in the rat striatum. Eur J Neurosci 11:481-490.

Guitart X, Thompson MA, Mirante CK, Greenberg ME, Nestler EJ (1992) Regulation of cyclic AMP response element-binding protein (CREB) phosphorylation by acute and chronic morphine in the rat locus coeruleus. J Neurochem 199258:1168-1170.

Hayward MD, Duman RS, Nestler EJ (1990) Induction of the c-fos proto-oncogene during opiate withdrawal in the locus coeruleus and other regions of rat brain. Brain Res 525:256-266.

Heimer L, Alheid G (1991) Piecing together the puzzle of basal forebrain anatomy. In: The basal forebrain: anatomy to function (Napier TC, Kalivas PW and Hanin I, eds)pp 1-42. New York: Plenum.

Heimer L, Harlan R, Alheid G, Garcia M, Olmos J (1997) Substantia innominata: a notion which impedes clinical-anatomical correlations in neuropsychiatric disorders. Neuroscience 76:957-1006.

Heinrichs S, Menzaghi F, Schulteis G, Koob G, Stinus L (1995) Suppression of corticotropin-releasing factor in the amygdala attenuates aversive consequences of morphine withdrawal. Behav Pharmacol 6:74-80.

Impey S, Smith DM, Obrietan K, Donahue R, Wade C, Storm DR (1998) Stimulation of cAMP response element (CRE)-mediated transcription during contextual learning. Nat Neurosci 1:595-601.

Jolas T, Nestler E, Aghajanian GK (2000) Chronic morphine increases GABA tone on serotonergic neurons of the dorsal raphe nucleus: association of an upregulation of the cyclic AMP pathway. Neuroscience 95:433-443.

Kasckow JW, Regmi A, Gill PS, Parkes DG, Geracioti TD (1997) Regulation of corticotropin-releasing factor (CRF) messenger ribonucleic acid and CRF peptide in the amygdala: studies in primary amygdalar culture. Endocrinology 138:4774-4782.

Konradi C, Cole R, Green D, Senatus P, Leveque JC, Pollack A, Grossbard S, Hyman SE (1995) Analysis of the proenkephalin second messenger-inducible enhancer in rat striatal cultures. J Neurochem 65:1007-1015.

Koob GF (1999) Stress, corticotropin-releasing factor, and drug addiction. Ann NY Acad Sci 897:27-45.

Koob GF, Le Moal M (2001) Drug addiction, dysregulation of reward, and allostasis. Neuropsychopharmacology 24:97-129.

Lane-Ladd S, Pineda J, Boundy V, Pfeuffer T, Krupinski J, Aghajanian GK, Nestler EJ (1997) CREB in the LC: biochemical, physiological and behavioural evidence for a role in opiate dependence. J Neurosci 17:7890-7901.

LeDoux JE (2000) Emotion circuits in the brain. Annu Rev Neurosci 23:155-184.

Maldonado R, Stinus L, Gold LH, Koob GF (1992) Role of different brain structures in the expression of the physical morphine withdrawal syndrome. J Pharmacol Exp Ther 261:669-677.

Maldonado R, Blendy JA, Tzavara E, Gass P, Roques BP, Hanoune J, Schutz G (1996) Reduction of morphine abstinence in mice with a mutation in the gene encoding Science 273:657-659.

Mansour A, Fox C, Akil H, Watson S (1995) Opioid-receptor mRNA expression in the rat CNS: anatomical and functional implications. Trends Neurosci 18:22-29.

Martin KC, Kandel ER (1996) Cell adhesion molecules, CREB, and the formation of new synaptic connections. Neuron 17:567-570.

Montminy M (1997) Transcriptional regulation by cAMP. Annu Rev Biochem 66:807-822.

Morgan JI, Curran T (1995) Immediate-early genes: ten years on. Trends Neurosci 18:66-67.

Nestler EJ (2001) Molecular basis of neural plasticity underlying addiction. Nat Rev Neurosci 2:119-128.

Nestler EJ, Aghajanian GK (1997) Molecular and cellular basis of addiction. Science 278:58-63.

Nestler EJ, Tallman JF (1988) Chronic morphine treatment increases cyclic AMP-dependent protein kinase activity in the rat locus coeruleus. Mol Pharmacol 33:127-132.

Nestler EJ, Hope BT, Widnell KL (1993) Drug addiction: a model for the molecular basis of neural plasticity. Neuron 11:995-1006.

Pham TA, Impey S, Storm DR, Stryker MP (1999) CRE-mediated gene transcription in neocortical neuronal plasticity during the developmental critical period. Neuron 22:63-72.

Pliakas AM, Carlson RR, Neve RL, Konradi C, Nestler EJ, Carlezon Jr WA (2001) Altered responsiveness to cocaine and increased immobility in the forced swim test associated with elevated CREB expression in the nucleus accumbens. J Neurosci 21:7397-7403.

Rasmussen K, Beitner DB, Krystal JH, Aghajanian GK, Nestler EJ (1990) Opiate withdrawal and the rat locus coeruleus: behavioral, electrophysiological, and biochemical correlates. J Neurosci 10:2308-2317.

Robbins TW, Everitt BJ (1996) Neurobehavioural mechanisms of reward and motivation. Curr Opin Neurobiol 6:228-236.

Rosetti ZL, Hmaidan Y, Gessa G (1992) Marked inhibition of mesolimbic dopamine release: a common feature of ethanol, morphine, cocaine and amphetamine abstinence in rats. Eur J Pharmacol 221:227-234.

Shaywitz A, Greenberg ME (1999) CREB: A stimulus-induced transcription factor activated by a diverse array of extracellular signals. Annu Rev Biochem 68:821-861.

Silva AJ, Murphy GG (1999) cAMP and memory: a seminal lesson from Drosophila and Aplysia. Brain Res Bull 50:441-442.

Sklair-Tavron L, Shi WX, Lane SB, Harris HW, Bunney BS, Nestler EJ (1996) Chronic morphine induces visible changes in the morphology of mesolimbic dopamine neurons. Proc Natl Acad Sci USA 93:11202-11207.

Spengler D, Rupprecht R, Van LP, Holsboer F (1992) Identification and characterization of a $3^{\prime}, 5^{\prime}$-cyclic adenosine monophosphate-responsive element in the human corticotropin-releasing hormone gene promoter. Mol Endocrinol 6:1931-1941.

Terwilliger RZ, Beitner-Johnson D, Sevarino KA, Crain SM, Nestler EJ (1991) A general roll for adaptations in G-proteins and the cyclic AMP system in mediating the chronic actions of morphine and cocaine on neuronal function. Brain Res 548:100-110.

Thome J, Sakai N, Shin K, Steffen C, Zhang YJ, Impey S, Storm D, Duman RS (2000) cAMP response element-mediated gene transcription is upregulated by chronic antidepressant treatment. J Neurosci 20:4030-4036.

Turgeon SM, Pollack AE, Fink JS (1997) Enhanced CREB phosphorylation and changes in c-Fos and FRA expression in striatum accompany amphetamine sensitization. Brain Res 749:120-126.

Unterwald EM, Cox BM, Kreek MJ, Cote TE, Izenwasser S (1993) Chronic repeated cocaine administration alters basal and opioidregulated adenylyl cyclase activity. Synapse 15:33-38.

Widnell K, Russel D, Nestler E (1994) Regulation of expression of cAMP response element-binding protein in the $\mathrm{LC}$ in vivo and in a LC-like cell line in vitro. Proc Natl Acad Sci USA 91:10947-10951.

Williams JT, Christie MJ, Manzoni O (2001) Cellular and synaptic adaptations mediating opioid dependence. Physiol Rev 81:299-343.

Yin JC, Tully T (1996) CREB and the formation of long-term memory. Curr Opin Neurobiol 6:264-268. 